\title{
Open BMSTU Platform and Teachers Training in Online Courses Development and Implementation Areas
}

\author{
Yury I. Dimitrienko ${ }^{1 *}$, Elena A. Gubareva ${ }^{1}$, Kirill M. Zubarev ${ }^{1}$, Victor Yu. Chibisov ${ }^{1}$, \\ Svetlana S. Kudryavtseva ${ }^{1}$, Sunnat B. Karimov ${ }^{1}$, and Elena N. Grigorieva ${ }^{1}$ \\ ${ }^{1}$ Bauman Moscow State Technical University, 2nd Baumanskaya str., 5/1, 105005, Moscow, Russia
}

\begin{abstract}
The article is devoted to the strategy for the development of digital education at the Bauman Moscow State Technical University. The theoretical and practical aspects of the development of online courses are considered, in accordance with the requirements of the National Open Education Platform (NOEP) using the Open BMSTU platform. The paper includes the program of the advanced training course for teachers in in online courses development and implementation areas, tested at the Bauman Moscow State Technical University.
\end{abstract}

\section{Introduction}

Institutions of higher education are increasingly adopting blended learning (BL), the combination of face-to-face and technology-mediated instruction [1].

The adoption of blended learning (BL), the combination of traditional face-to-face and technology-mediated instruction, is increasing in higher education around the world. In fact, scholars have predicted that BL will become the "new traditional model" [2] or the "new normal" in higher education course delivery [3].

Institutions implementing BL should identify the goals they intend to achieve [4]. Graham, Allen, and Ure [5] cited three general purposes for BL adoption: (1) enhanced pedagogy, (2) increased access and flexibility, and (3) improved cost-effectiveness and resource use.

BL may provide pedagogical benefits such as increased learning effectiveness, satisfaction, and efficiency [6,7]. The University of Central Florida (UCF) conducted a multi-year study examining the success rates of tens of thousands of their face-to-face, BL, and online students. UCF reported that the success rates for BL were higher within each college than either fully face-to-face or fully online courses for both males and females $[7,8]$.

Successful BL implementation requires advocacy among administrators, faculty, and other institutional personnel $[9,15]$.

Establishing necessary technological infrastructure is central to the success of BL implementation [16]. Institutions seeking to implement BL must provide the core

*Corresponding author: dimit@bmstu.ru 
technological infrastructure required for an effective course management system that is user friendly for faculty and students $[15,17]$.

Once a clear policy direction is in place, an institution must establish the necessary physical and technological infrastructure [6], which may include elements such as computers and other hardware, internet access, and necessary software [18].

Bauman Moscow State Technical University (BMSTU), being a leading technical university in Russia, has begun implementing its own strategy for the development of digital educational technologies, which allows to overcome the problems of introducing online education into the educational process and create a fundamentally new educational system based on modern digital educational technologies [19-23].

The basis of the strategy for the development of digital education at the University is the creation and implementation of digital blended learning in the educational process, the main emphasis is placed on full-time education using specialized electronic educational resources (EER). At the same time, given the globalization of the educational space, attention should be paid to the development of electronic educational resources in the form of online courses, which are in demand by the external environment for distance and correspondence education.

For this purpose, the University has created a digital educational environment that allows teaching using new tools in the form of electronic educational resources, including in the form of online courses.

This educational environment should allow for the implementation of the following new learning principles:

- increasing the motivation of students through the introduction of computer visualization of the studied images of knowledge;

- the ability to build individual trajectories for training engineering personnel with a clear preservation of the logical structure of knowledge and the competence principle of building knowledge;

- $\quad$ ensuring a systematic approach to education based on a unified logical structure of knowledge.

\section{The Open BMSTU platform}

In the summer of 2017, the Department "Computational Mathematics and Mathematical Physics" (FS-11) of the Fundamental Sciences Faculty (FS) of Bauman Moscow State Technical University began working on the development of online math courses. At that time, for the BMSTU, this work was completely new, although it was already actively carried out in other universities. After completing advanced training on the National Open Education Platform (NOEP), the department created its own video studio and began work on the creation of an online course Analytical Geometry, which was based on new digital technologies, which further led to the creation of an independent digital platform - Digital Learning System Nomotex (DLS Nomotex) intended for digital mathematical education of engineers [11-14]. The main work of the video studio was conducted by K.M. Zubarev. The authors of the online course on Analytical Geometry were Yu.I. Dimitrienko, E.A. Gubareva and S.V. Sborshikov.

In order to expand the department's experience in developing online courses, in July 2017, by order of the rector, the Open BMSTU platform was organized, which could host and operate online courses created at BMSTU. Yu.I. Dimitrienko became the head of the platform. Work on the creation of the first 2 digital courses - Mathematical Analysis and Analytical Geometry on the DLS Nomotex platform and the Analytical Geometry online course continued until the autumn of 2018. 
The Open BMSTU platform, designed to host and operate online courses, electronic interactive courses and other electronic educational resources, is based on the Open edX platform (Fig. 1).

The platform currently hosts 27 online courses, 18 e-learning courses, and 12 e-courses for blended (hybrid) learning.

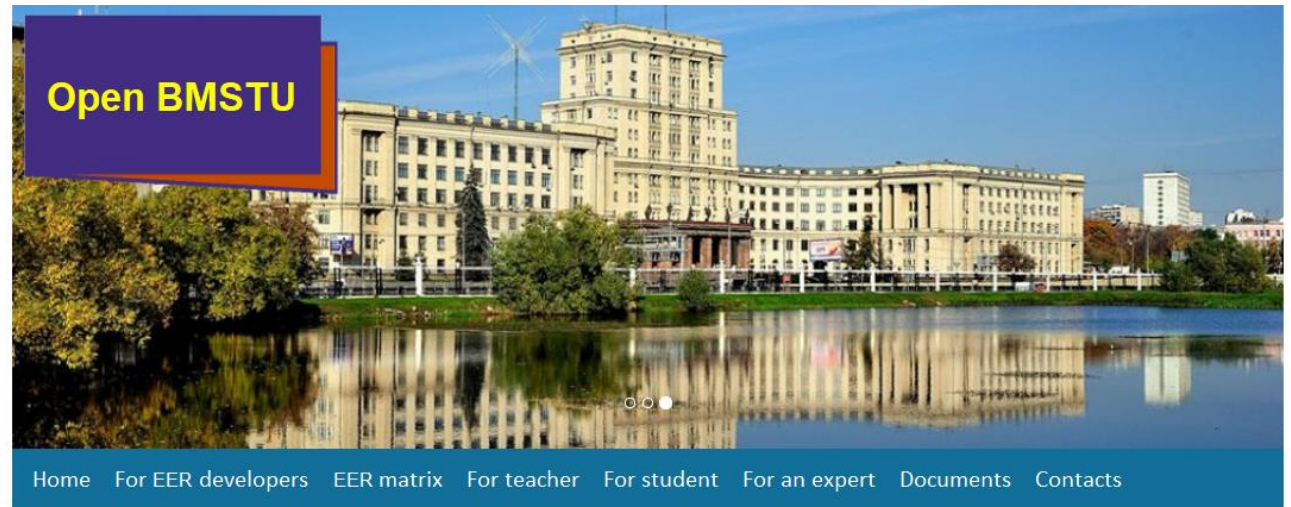

Platforms:

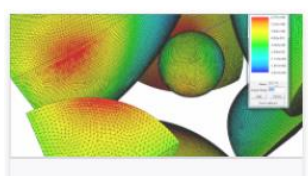

NOMOTEX

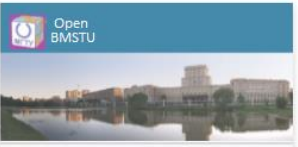

BMSTU Online

News:

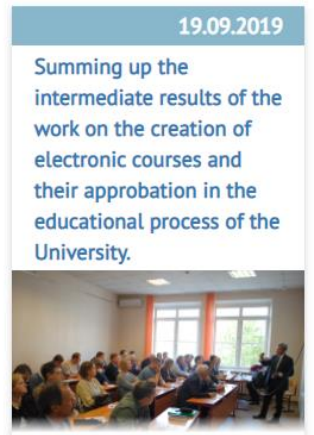

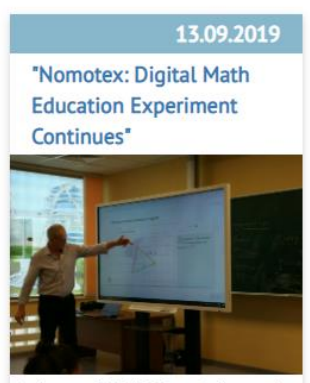

In the new 2019/2020 academic year, the experiment on digital mathematics

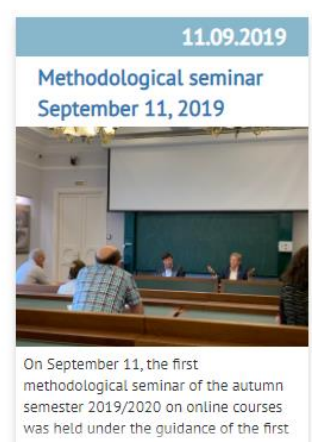

Fig. 1. The Open BMSTU platform.

\subsection{The structure of the Open BMSTU platform}

Currently, the Open BMSTU platform has 2 main subsystems:

- the BMSTU-online platform, designed for the placement and functioning of online courses;

- Electronic Educational Resources (EER) storage system: video lectures, video seminars, and other electronic materials intended for distance learning.

At present, 27 online courses in various areas have been published in the BMSTUonline platform (Fig. 2), including: Analytical geometry, Linear algebra, Descriptive geometry, Management, Life safety and others. The Open BMSTU platform is used throughout the educational process by three main groups of users: online course developers, teachers and students. All online courses are developed and supported by leading teachers and staff of the university departments. 


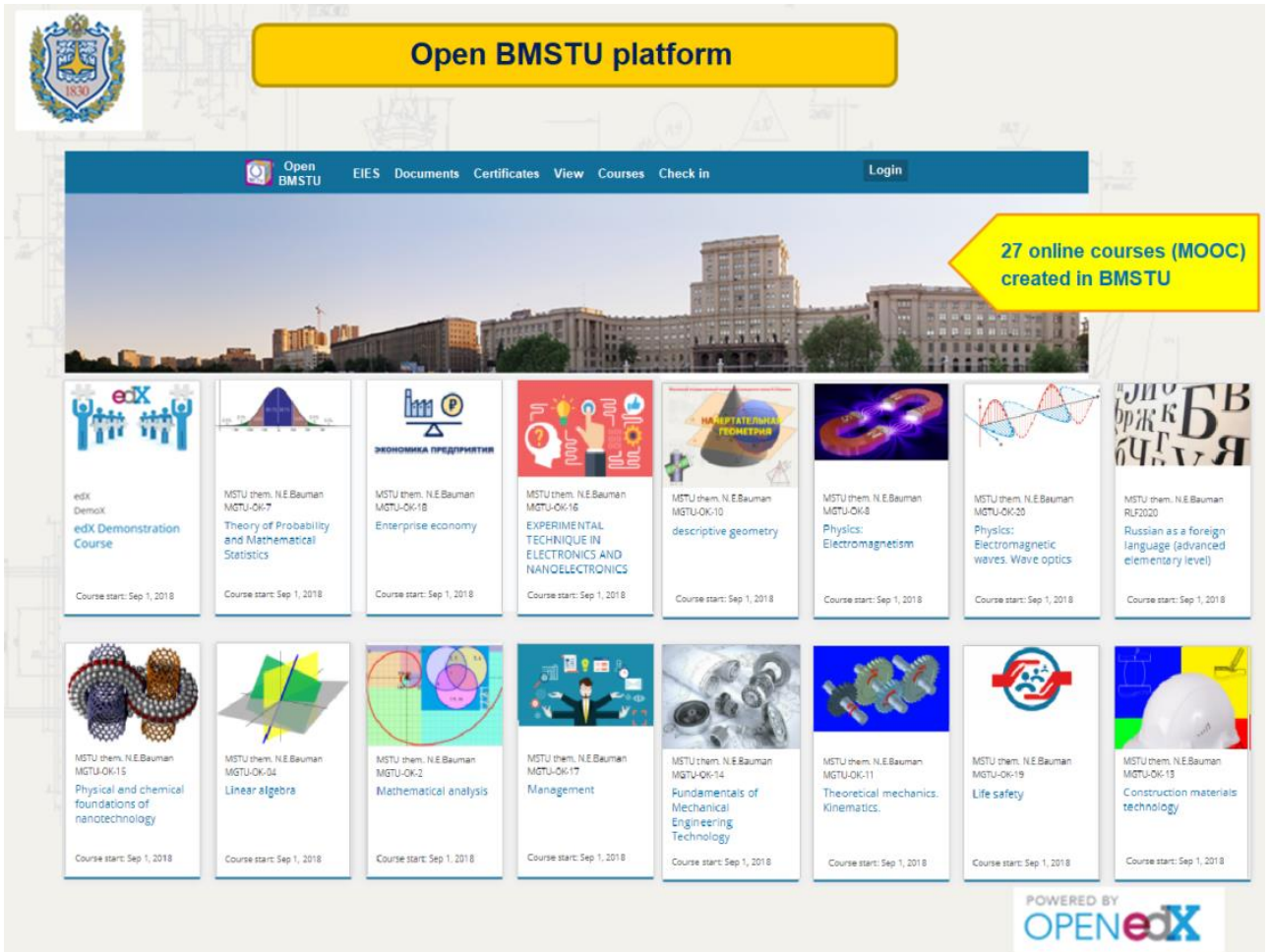

Fig. 2. The BMSTU-online platform (subsystem of the Open BMSTU platform).

The published online courses consist of video lectures, video seminars, homework assignments, current and midterm quizzes. The teacher provides access to the course materials, structures them, and makes the necessary changes. The platform gives students the opportunity to quickly and effectively interact with the teacher, and the teacher to monitor progress and evaluate the knowledge gained.

Online courses published on the BMSTU-online platform are developed in accordance with the requirements of Federal State Educational Standards of Figher Education (FSES HE) or Self-Established Educational Standards for Higher Education (SEES HE), and also comply with the requirements of the National Open Education Platform.

The Electronic Educational Resources (EER) storage system is a system that allows you to:

- it is easy for any teacher to download and store various types of EER in pdf, ppt, mp4 formats, as well as in the form of links to online courses, video lectures and seminars, electronic interactive courses and electronic educational publications (Fig. 3);

- $\quad$ pro-rectors, deans, heads of departments and other leaders to monitor the materials posted by teachers;

- for students to view the EER and download some of the necessary materials. 
EER, developed by the Department FS11

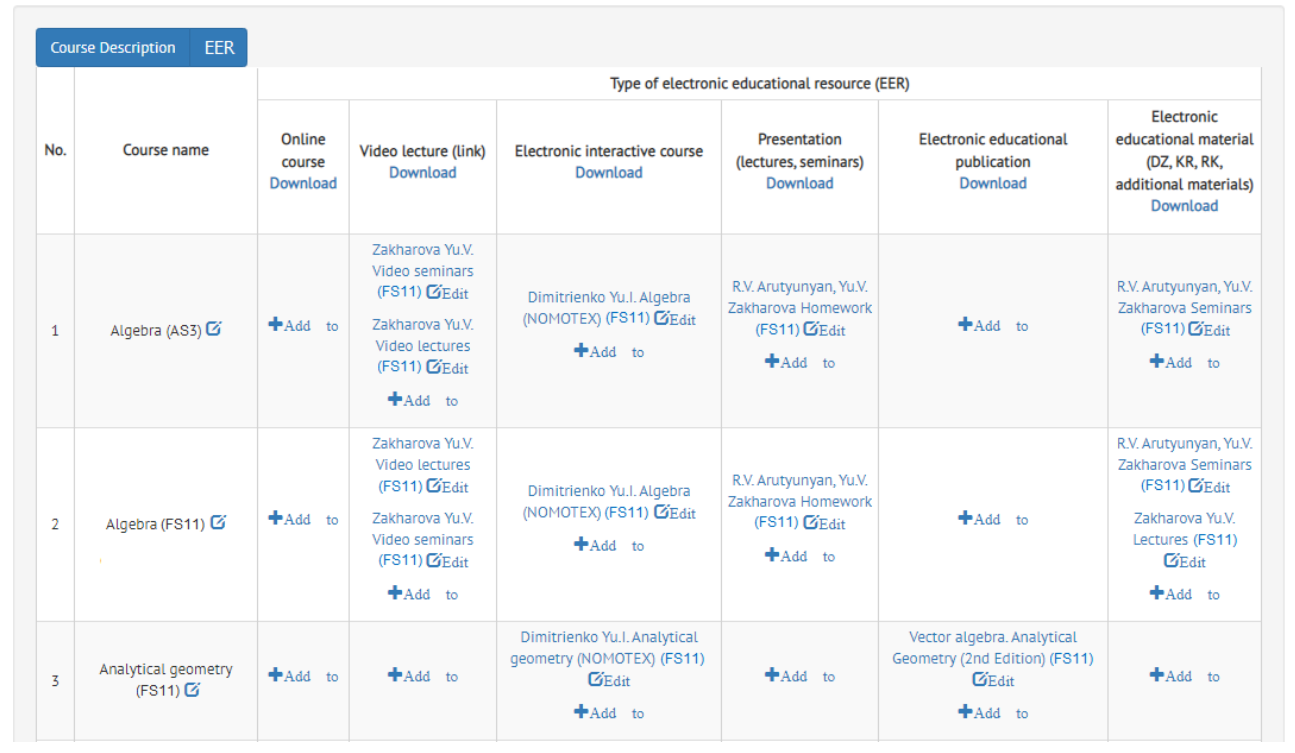

Fig. 3. Electronic Educational Resources (EER) storage system of the Open BMSTU platform.

\section{Teachers Training in online courses development and implementation areas}

The main trend in education at the present time is the creation of massive open online courses in disciplines taught in higher educational institutions. Such courses will be useful and interesting not only for students, but also for specialists wishing to undergo retraining, change their profession and occupation [11-14].

M.H. Martin stressed that instructors who are creating online courses need pedagogical and technological professional development [10].

The development of online courses is currently an integral part of the teacher's methodological work. In the future, it is very likely that the main work of the teacher will shift towards the creation, maintenance and support of electronic educational resources, primarily online courses. In this sense, the teacher's mastery of competencies in the field of creating online courses seems to be extremely relevant.

The Department FS-11 of BMSTU developed a teachers training course for online courses development and implementation areas

To pass the advanced training course, basic knowledge in the use of MS Office, special knowledge in the discipline in which the trainees will create a trial author's online course, as well as possession of certain skills of working with a personal computer are required.

The purpose of the course is to teach trainees the practical skills of developing online courses at a technical university that meet the requirements of the National Open Education Platform, as well as the Open BMSTU platform. The acquired knowledge is supposed to be used in the professional activities of teachers to create online courses [12].

After completing the advanced training course, trainees should have an understanding of modern online courses and the main platforms for their placement. In the course of training, trainees should master the skills of developing an algorithm for an online course using a standard template, as well as acquire skills in developing an algorithm for an author's online 
course [13]. As part of the course, trainees will learn the basic principles of creating a director's script, as well as gain skills in creating tests for conducting control events on online education platforms $[11,12]$.

\subsection{Planned learning outcomes}

It is assumed that trainees enrolled in the course "Development of online courses at the technical university" are able to independently master and use new research methods, to master new areas of professional activity, as well as apply modern methods and technologies for organizing educational activities, diagnostics and quality assessment educational process for various educational programs [12].

Based on the results of the course, trainees should

To Know:

- $\quad$ the concept of an online course. MOOK courses;

- $\quad$ concept for the storage and functioning of online courses;

- $\quad$ basic requirements for online courses prepared for the NOEP platform;

- detailed structure of the online course;

- basic requirements for the sections of the detailed structure of the online course;

- the main stages of work on the preparation of online courses;

- the concept of a director's script for an online course;

- $\quad$ principles of the formation of test and control works to check the development of the online course;

- $\quad$ principles of preparing video materials for an online course.

To be able to:

- $\quad$ develop an algorithm for creating an online course using a standard template;

- create a presentation of an online course in MS PowerPoint;

- $\quad$ create a director's script for an author's online course;

- $\quad$ prepare video materials for the online course;

To Own:

- develop tests and tests to check the mastery of the online course.

- skills in developing an algorithm for an online course using a standard template;

- $\quad$ skills in developing an algorithm for the author's online course;

- $\quad$ skills of creating a presentation of an online course in MS PowerPoint;

- $\quad$ skills of creating a director's script for an author's online course;

- $\quad$ skills in preparing video materials for an online course;

- $\quad$ skills in the development of tests and tests to check the mastering of the online course.

\subsection{Course program}

As part of the first lesson, trainees are invited to delve into the terminology of online courses, as well as get acquainted with existing platforms for online learning: the National Open Education Platform, Cursera, the Open Polytech platform, the TPU platform, the Open BMSTU platform. The practical part of the advanced training course is aimed at creating 1 video lecture and one testing in a specialized or general education subject. The first lesson of the practical part is also for informational purposes, where the listener is invited to get acquainted with the site of Open Education platform and personally test the functionality of the platform $[12,13]$. 
The topic of lecture 2 is "Basic requirements for online courses hosted on the National Open Education Platform and Open BMSTU, and an algorithm for developing an online course prepared for placement on these platforms." In this lesson, the following aspects are discussed:

- The concept of the detailed structure of an online course;

- Basic requirements for the sections of the detailed structure of the online course;

- The main stages of work on the preparation of online courses.

The simplest and most accessible program for creating materials for recording video lectures is MS PowerPoint-13 and 16. The toolkit of this program allows you to create animated lectures, with the ability to highlight the key moments of the lesson.

At the 3rd lecture session, trainees are introduced to the capabilities of PowerPoint $[11,12]$.

In practical lesson 3, the trainees themselves need to create fragments of the presentation, which will be used in subsequent practical lessons and for recording video lectures.

The fourth lecture of the practical lesson is devoted to acquaintance with the concept of a director's script. The lesson deals with the main stages of creating a director's script. Trainees are taught how to form the content of the online course module section: video lectures, presentations, control and test tasks. As part of the lecture, the technique of creating reference text and key phrases for changing the slide is analyzed. As part of a practical lesson, trainees are encouraged to create a trial director's script [13].

In the 5th lesson, the main attention is paid to the preparation of video materials for the online course, as well as work on video filming of the online course in the studio. The main topics of the lesson:

- General algorithm for preparing video materials;

- Basic technical requirements for video materials;

- Basic technical requirements for video, audio;

- Basic requirements for the quality characteristics of the sound track;

- Basic requirements for video quality characteristics;

- Various types of tasks with automatic check of the answer: tasks of a closed type, tasks of an open type, tasks, tasks for establishing a sequence, tasks for establishing correspondence;

- Timing of online course module and video.

Practical lesson on topic 5 is devoted to the development of trial verification and control measures for the author's online course.

In the last lesson, trainees are introduced to the problems that can arise when creating an online course, as well as when uploading a course to open education platforms. In this lecture, teachers are introduced to the main aspects of supporting the course after the first trainees begin to take it. During the practical lesson, trainees of the refresher course should record a trial video lecture.

In the spring of 2018, the Department FS-11 organized the first advanced training course on the development of online courses. The leaders of the advanced training course were Yu.I. Dimitrienko, E.A. Gubareva, K.M. Zubarev. This course was attended by about 20 teachers of the faculties: Fundamental Science (FS), Materials and Technologies (MT), and others, as a result, work began on the creation of the first stage of online courses at the BMSTU. The work lasted for about a year and ended with the placement of about 12 online courses on the Open BMSTU platform. 


\section{Blended learning in BMSTU}

The BMSTU-online platform can be used as a tool for blended learning. The teacher uses the BMSTU-online platform to visualize materials from lectures and seminars, as well as to conduct control events. Students can independently and in advance familiarize themselves with the basic materials of the course, do their homework using the necessary materials posted on the platform and available to listeners at any time with mobile devices and personal computers.

One of the main functions of the BMSTU-online platform is the organization of constant objective control of the educational process based on testing and carrying out current and intermediate control with the use of EER, since the result of monitoring the educational process is the most important criterion for assessing the quality of education. The test results help the teacher to determine the quality of the students' assimilation of the educational material, the level of mastering the knowledge, abilities and skills provided by the course program.

The use of EER in the course of current and intermediate control makes it possible to increase the efficiency of the educational process, as well as to reduce the load on the teacher, by reducing the time spent on checking students' work. Testing is an objective way of assessing knowledge, which is achieved by standardizing the procedure for conducting and evaluating the results. However, to ensure objectivity and fairness of test results, it is necessary to constantly replenish the base of test items.

Since 2018 at the BMSTU, the introduction of digital blended learning into the educational process has begun at the faculties of Fundamental Sciences (FS), Power Engineering (E), Aerospace (AS), Mechanical Engineering (SM), Engineering Technology (MT), Engineering Business and Management (IBM), Computer Science and Control Systems (IU), Electronics and Laser Technology (RL), Linguistics (L), and Preparatory Department of the Faculty of International Educational Programs (POD FIEP) in 14 courses created by the departments of FS-11, FS-3, L-1, RK-1, MT-3, MT-13, IBM-2, IBM-4, E-9: Mathematical analysis; Analytic geometry; Algebra; Integrals and Differential Equations; Linear algebra and functions of several variables; Theory of functions of a complex variable; Theoretical mechanics; Russian as a foreign language; Engineering graphics; Mechanical Engineering Technology; Construction materials technology; Enterprise economy; Management; Life safety.

During the experiment, the following blended learning principles were observed:

- Consistency: the student independently studies the current material on e-courses at a convenient time for himself, and then in the classroom, together with the teacher, works through, deepens the educational material, and then applies knowledge in practice;

- Visibility: the student can use the necessary electronic educational resources (video lectures, video seminars, online courses, etc.) published on the platform, which are available at any time with mobile devices and personal computers;

- Practical application: for the assimilation of the theory, practical classes, homework, solving cases and conducting current and intermediate control using electronic resources are required;

- Continuity: on the one hand, the student can always get a "new portion" of the material, and on the other hand - regular control of knowledge, organization of "micro-controls";

- Support: in blended learning, the student can always ask the teacher a question and get an answer, without waiting for the next face-to-face lesson.

Some results of introducing digital blended learning into the educational process:

- increasing students' interest in new "live" and more "friendly" forms of education; 
- increasing the activity of students, due to the fact that electronic materials are available to them during the entire period of study;

- improving academic performance, due to a higher and unified system of requirements for the control of knowledge using automated verification tools.

The overall assessment by course developers and trainers who delivered classes using blended learning technology is generally positive. The attendance and academic performance of students has increased, there is an opportunity to improve the level of the discipline being studied. However, during the experiment, the teachers also encountered problems, mostly technical problems. It is worth noting that the work on the creation of electronic courses provided for high qualifications of teachers and required an additional significant investment of time.

\section{Conclusions}

Bauman Moscow State Technical University has developed its own platform Open BMSTU, intended for blended learning - face-to-face classes using presentations, automated knowledge assessment and online courses, and an advanced training program for teachers in the development and use of online courses. More than 50 teachers of the BMSTU to develop the creation of online courses, which during 2018-2019 created more than 20 online courses in basic disciplines, these online courses are hosted and are currently operating on the Open BMSTU platform.

An original digital blended learning technology was developed using online courses. Experience in using blended learning at BMSTU showed that, despite certain difficulties associated mainly with the technical equipment of classrooms, increased labor costs for developing online courses and conducting the classes themselves, the positive effect of the introduction of mixed technology is quite obvious: it is possible to increase student performance, the depth of the studied students of knowledge, to make the learning process more convenient, comfortable and attractive for students.

\section{References}

1. W.W. Porter, C.R. Graham, K.A. Spring \& K.R. Welch, Blended learning in higher education: Institutional adoption and implementation, Computers \& Education, 75, pp. 185-195 (2014)

2. B. Ross \& K. Gage, Global perspectives on blending learning, The Handbook of Blended Learning; Bonk, JC, Graham, RC, Eds, pp. 155-168 (2006)

3. A. Norberg, C.D. Dziuban \& P.D. Moskal, A time-based blended learning model, On the Horizon (2011)

4. P. Moskal, C. Dziuban \& J. Hartman, Blended learning: A dangerous idea?, The Internet and Higher Education, 18, pp.15-23 (2013)

5. C.R. Graham, S. Allen \& D. Ure, Benefits and challenges of blended learning environments, In Encyclopedia of Information Science and Technology, First Edition pp. 253-259 (2005)

6. D.R. Garrison \& H. Kanuka, Blended learning: Uncovering its transformative potential in higher education, The internet and higher education, 7(2), pp. 95-105 (2004)

7. C.R. Graham, Emerging practice and research in blended learning, Handbook of distance education, 3, pp. 333-350 (2013) 
8. C. Dziuban, J. Hartman, P. Moskal, S. Sorg \& B. Truman, Three ALN modalities: An institutional perspective, Elements of quality online education: Into the mainstream, $\mathbf{5}$, pp. 127-148 (2004)

9. R. O'Dowd, Telecollaborative networks in university higher education: Overcoming barriers to integration, The Internet and higher education, 18, pp. 47-53 (2013)

10. M. H. Martin, Factors influencing faculty adoption of Web-based courses in teacher education programs within the State University of New York (Doctoral dissertation, Virginia Tech, 2003)

11. Yu.I. Dimitrienko, E.A. Gubareva, New technology of mathematical training of engineering personnel, based on a neural network model of knowledge, Innovation in education, No. 11, pp. 129-140 (2017)

12. Yu.I. Dimitrienko, E.A. Gubareva, K.M. Zubarev, S.S. Kudryavtseva, Methodological support of the continuing education of teachers on the development of online courses at bmstu, Science diary, No. 11 (2018)

13. Yu.I. Dimitrienko, E.A. Gubareva, Neural network model of mathematical knowledge and development of information and educational environment for mathematical training of engineers, Journal of Physics: Conference Series, Vol. 1141012010 (2018) doi:10.1088/1742-6596/1141/1/012010

14. Yu.I. Dimitrienko, E.A. Gubareva, T.V. Oblakova, Methodology for assessing knowledge on the course "Mathematical Analysis" in the digital environment NOMOTEX, Innovative development, No. 9, pp. 8-11 (2018)

15. J.A. Taylor \& D. Newton, Beyond blended learning: A case study of institutional change at an Australian regional university, The Internet and Higher Education, 18, pp. 54-60 (2013)

16. M. Niemiec \& G. Otte, An Administrator's Guide to the Whys and Hows of Blended Learning, Journal of Asynchronous Learning Networks, 13(1), pp. 19-30 (2009)

17. Y.H. Liu \& M. Tourtellott, Blending at small colleges: Challenges and solutions, Journal of Asynchronous Learning Networks, 15(1), pp. 58-67 (2011)

18. A. Powell, A case study of e-learning initiatives in New Zealand's secondary schools (Doctoral Dissertation, 2011)

19. V. Mayorova, O. Zhdanovich, Innovative collaborative educational programs for space systems engineers, Proceedings of the International Astronautical Congress, IAC (2016)

20. G. Procurat, A. Strukova, A. Vukolov, O. Egorova, Generated graphics and game development software in engineering education: Perspectives and experience of usage, Mechanisms and Machine Science, No. 64, pp. 123-130 (2019)

21. N. Serdyukova, V. Serdyukov, S. Neustroev, Testing as a feedback in a smart university and as a component of the identification of smart systems, Smart Innovation, Systems and Technologies, No. 144, pp. 527-538 (2019)

22. V. Guznenkov, P. Zhurbenko, The Academic Discipline 'Computer Graphics' for the Open Education System, 2018 4th International Conference on Information Technologies in Engineering Education, Inforino 2018 - Proceedings 8581738 (2018)

23. A. Karpov, Education for knowledge society: Learning and scientific innovation environment, Journal of Social Studies Education Research, No. 8(3), pp. 201-214 (2017) 